Article

\title{
Preparation of Amino-Functionalized Mesoporous SBA-15 Nanoparticles and the Improved Adsorption of Tannic Acid in Wastewater
}

\author{
Tzong-Horng Liou ${ }^{1,2, *(\mathbb{D})}$, Guan-Wei Chen ${ }^{1}$ and Shang Yang ${ }^{1}$ \\ 1 Department of Chemical Engineering, Ming Chi University of Technology, 84 Gungjuan Road, Taishan \\ District, New Taipei City 24301, Taiwan; u06137029@gmail.com (G.-W.C.); a0981578295@gmail.com (S.Y.) \\ 2 Battery Research Center of Green Energy, Ming Chi University of Technology, 84 Gungjuan Road, \\ Taishan District, New Taipei City 24301, Taiwan \\ * Correspondence: thliou@mail.mcut.edu.tw; Tel.: +886-229-089-899 (ext. 4617)
}

check for updates

Citation: Liou, T.-H.; Chen, G.-W.;

Yang, S. Preparation of

Amino-Functionalized Mesoporous SBA-15 Nanoparticles and the

Improved Adsorption of Tannic Acid in Wastewater. Nanomaterials 2022, 12, 791. https://doi.org/10.3390/ nano12050791

Academic Editor: Christos

A. Aggelopoulos

Received: 7 February 2022

Accepted: 24 February 2022

Published: 26 February 2022

Publisher's Note: MDPI stays neutral with regard to jurisdictional claims in published maps and institutional affiliations.

Copyright: (c) 2022 by the authors. Licensee MDPI, Basel, Switzerland. This article is an open access article distributed under the terms and conditions of the Creative Commons Attribution (CC BY) license (https:/ / creativecommons.org/licenses/by/ $4.0 /)$.

\begin{abstract}
Ordered mesoporous Santa Barbara amorphous (SBA-15) materials have high surface areas and are widely used in adsorption, separation, filtration, and heterogeneous catalytic processes. However, SBA-15 surfaces contain hydroxyl groups that are unsuited to the adsorption of organic pollutants; thus, SBA-15 must be chemically modified to promote its adsorption activity. In this study, amino-functionalized nanoporous SBA-15 was fabricated by employing sodium silicate as a precursor. The structural characteristics of the prepared composites were examined using thermogravimetric analysis, X-ray diffraction, Fourier transform infrared spectrometry, field-emission scanning electron microscopy, transmission electron microscopy, and surface area analysis. The prepared SBA-15 had a large pore size $(6.46-7.60 \mathrm{~nm})$, large pore volume $\left(1.037-1.105 \mathrm{~cm}^{3} / \mathrm{g}\right)$, and high surface area $\left(546-766 \mathrm{~m}^{2} / \mathrm{g}\right)$. Functionalization caused a reduction in the SBA-15 pore volume and surface area, whereas amino groups that promoted an interaction between adsorbates and solids facilitated solute adsorption. The adsorption of tannic acid (TA) onto amino-modified silica composites (SBA-15 and 3-aminopropyltriethoxysilane (SBA-15/APTES) and SBA-15 and pentaethylenehexamine (SBA15/PEHA)) was studied. Their adsorption capacities were affected by solution temperature, solution $\mathrm{pH}$, agitation speed, adsorbent dosage, and initial TA concentration. The maximum adsorption capacities for SBA-15/APTES and SBA-15/PEHA were 485.18 and $413.33 \mathrm{mg} / \mathrm{g}$, respectively, with SBA-15/APTES exhibiting ultrafast removal of TA ( $98.61 \%$ removal rate at $15 \mathrm{~min})$. In addition, this study explored the thermodynamics, adsorption isotherms, and kinetics. A comparison of two types of amino-functionalized SBA-15 was used for the first time to adsorb TA, which providing valuable information on TA adsorption on high adsorption capacity materials in water media.
\end{abstract}

Keywords: SBA-15; amino groups; adsorption; tannic acid; mesostructure

\section{Introduction}

Nanomaterials are widely applied in many fields such as pharmaceutics, energy, semiconductors, and the environment [1,2]. The synthesis of SBA-15 nanomaterials has attracted considerable attention since Chmelka et al. developed the process in 1998 [3]. According to the International Union of Pure and Applied Chemistry, mesoporous materials have pore sizes of 2-50 nm, and SBA-15 materials possess uniform mesopores, a high pore volume, large specific surface area, and stability, making them suitable for numerous applications related to adsorption [4], catalysis [5], tissue engineering [6], drug release [7], $\mathrm{CO}_{2}$ capture [8], and energy cells [9]. SBA-15 is prepared in an acidic environment through the interaction between a surfactant template and silicon precursor, producing a two-dimensional and well-ordered hexagonal structure. As compared with microporous materials, such as zeolites, mesoporous SBA-15 material has large pore sizes (approximately 10-30 nm), which can decrease mass transfer resistance for large adsorbates, making it a potential material 
for the adsorption of wastewater. Sodium silicate $\left(\mathrm{Na}_{2} \mathrm{SiO}_{3}\right)$ and tetraethyl orthosilicate (TEOS) are both typically used as a silicon source to synthesize SBA-15 materials $[10,11]$. However, the high-priced TEOS reagent increases the cost of raw materials. By contrast, sodium silicate is a low-cost silicon source for the mass manufacture of SBA-15. Converting sodium silicate into mesoporous silica materials can eliminate hazardous pollutants from wastewater and air.

Tannic acid (TA) is an organic compound that is frequently found in surface and drinking water [12]. TA is also a raw material used in many industries, including in the manufacturing of ink, medicines, paper, and leather products [13]. Recently, TA has raised concerns because of its toxicity to aquatic animals and plants [14]. Furthermore, in drinking water, TA can interact with chlorine in a manner that is hazardous to human health. Therefore, removing TA from water media is essential. Many methods, such as adsorption, membrane separation, biological processes, ion exchange, coagulation, and chemical oxidation, have been used to remove TA from aqueous solutions [15]. Adsorption is considered the most efficient method because it is less expensive, highly efficient, and straightforward [16].

Because it contains $\mathrm{Si}-\mathrm{OH}$ and $\mathrm{Si}-\mathrm{O}$ groups, the exterior of SBA-15 has a negative charge density. This makes it unsuitable for TA adsorption because organic molecules have a negative charge. Surface modification of SBA-15 with amino groups is effective in improving the adsorption activity. Castaldo et al. [17] prepared amino-functionalized hypercrosslinked resins through a nitration-reduction process. Functionalization can promote the evolution of microporous structures, which effectively increase the adsorption of polar dyes and $\mathrm{CO}_{2}$. Melnyk et al. [18] used a one-stage sol-gel method to synthesize amino silica spherical particles. The highest adsorption capacity values for acid red, fluorescein, and methylene blue dyes were 262,132 , and $146 \mathrm{mg} / \mathrm{g}$, respectively. Tang et al. [19] synthesized polyethyleneimine-modified silica nanoparticles containing abundant amino groups. The maximum adsorption capability of acid organic II was as high as $705.3 \mathrm{mg} / \mathrm{g}$. Babapour et al. [20] used a solvothermal method to fabricate a metal organic framework (MOF), which was then amino functionalized using triethylamine. The highest adsorption amount for $\mathrm{Cr}$ (VI) was $78.12 \mathrm{mg} / \mathrm{g}$. Huang et al. [21] used the functionalization of chitosan by using tetraethylenepentamine to adsorb eosin $\mathrm{Y}$ dye. The highest amount of adsorption $(292.4 \mathrm{mg} / \mathrm{g})$ was observed at $25^{\circ} \mathrm{C}$.

In this study, two types of amino groups (aminopropyltriethoxysilane and pentaethylene hexamine) were used for the functionalization of SBA-15 to improve TA adsorption. SBA-15 was prepared with a surfactant template and sodium silicate precursor by using a hydrothermal treatment method. The effects of the calcination temperature, calcination time, hydrothermal treatment temperature, and hydrothermal treatment time on the pore textures of the SBA-15 specimens were observed. The surface characteristics and physical properties of specimens were examined. Furthermore, the adsorption of TA on SBA-15 materials after surface modification of amino groups was explored. The influences of the experimental parameters, such as solution temperature, solution $\mathrm{pH}$, agitation speed, adsorbent dosage, and initial TA concentration, on the elimination of TA were also explored. Finally, the thermodynamics (entropy, enthalpy, and Gibbs free energy), isotherm adsorption (Freundlich and Langmuir equations), and kinetics data (pseudo-first-order and pseudo-second-order models) were evaluated.

\section{Materials and Methods}

\subsection{Materials}

Sodium silicate $\left(\mathrm{Na}_{2} \mathrm{O}\left(\mathrm{SiO}_{2}\right)_{\mathrm{x}}\left(\mathrm{H}_{2} \mathrm{O}\right)_{\times}, \mathrm{SiO}_{2} \sim 26.5\right.$ wt. $\%, \mathrm{Na}_{2} \mathrm{O} \sim 10.6$ wt. $\left.\%\right)$, 3-aminopro pyltriethoxysilane (APTES), pluronic triblock copolymer (P123, $\left.\mathrm{EO}_{20} \mathrm{PO}_{70} \mathrm{EO}_{20}\right)$, and TA $\left(\mathrm{C}_{76} \mathrm{H}_{52} \mathrm{O}_{46}, 1701 \mathrm{~g} / \mathrm{mol}\right)$ were obtained from Sigma-Aldrich (Taufkirchen, Germany). Pentaethylene hexamine (PEHA), ethanol (99.9 wt.\%), hydrochloric acid, sodium hydroxide, and sulfuric acid were purchased from Merck (Gernsheim, Germany). High-purity (99.995\%) mixed gas $\left(79 \% \mathrm{~N}_{2}\right.$ and $\left.21 \% \mathrm{O}_{2}\right)$ was purchased from Sun $\mathrm{Fu}$ (Taipei, Taiwan). 


\subsection{Synthesis of the SBA-15 Materials}

The SBA-15 specimens were fabricated utilizing sodium silicate as the silicon precursor and P123 as the template [22,23]. For a representative experiment, $2.0 \mathrm{~g}$ of P123 was added to $60 \mathrm{~mL}$ of $2.0 \mathrm{M} \mathrm{HCl}$ solution under continuous stirring at $300 \mathrm{rpm}$ and $35^{\circ} \mathrm{C}$. Then, sodium silicate $(5.2 \mathrm{~g})$ was dissolved slowly into the P123 solution with agitation at $600 \mathrm{rpm}$ and $35^{\circ} \mathrm{C}$. The suspension was stirred for $24 \mathrm{~h}$, and then placed in a Teflon-lined autoclave. After heating the mixture at $100{ }^{\circ} \mathrm{C}$ for $24 \mathrm{~h}$, a white precipitate was collected through filtration and washed by distilled water. The solid was dried at $60{ }^{\circ} \mathrm{C}$ for $24 \mathrm{~h}$. Then, SBA-15 was acquired by calcining the solid in air at $550{ }^{\circ} \mathrm{C}$ for $6 \mathrm{~h}$.

\subsection{Synthesis of the Amino-Functionalized SBA-15 Specimens}

Using a reflux apparatus, $2.0 \mathrm{~g}$ of SBA-15 and $2.0 \mathrm{~g}$ of APTES were mixed in $60 \mathrm{~mL}$ of anhydrous alcohol at $78{ }^{\circ} \mathrm{C}$ for $24 \mathrm{~h}$ [24]. The sediment was repeatedly rinsed with ethanol, and then dried in a vacuum oven at $60^{\circ} \mathrm{C}$. The collected sample was marked as SBA-15/APTES. In addition, $1.0 \mathrm{~g}$ of PEHA was dissolved in $50 \mathrm{~mL}$ of ethanol under agitation for $40 \mathrm{~min}$ [25]. After adding $2.0 \mathrm{~g}$ of SBA-15, the mixture was heated under reflux at $80^{\circ} \mathrm{C}$ for $4 \mathrm{~h}$. Finally, the specimen was dried in a vacuum oven at $60^{\circ} \mathrm{C}$. The collected specimen was marked as SBA-15/PEHA. Figure 1 shows a schematic representation for synthesis of amino-functionalized SBA-15 specimens.

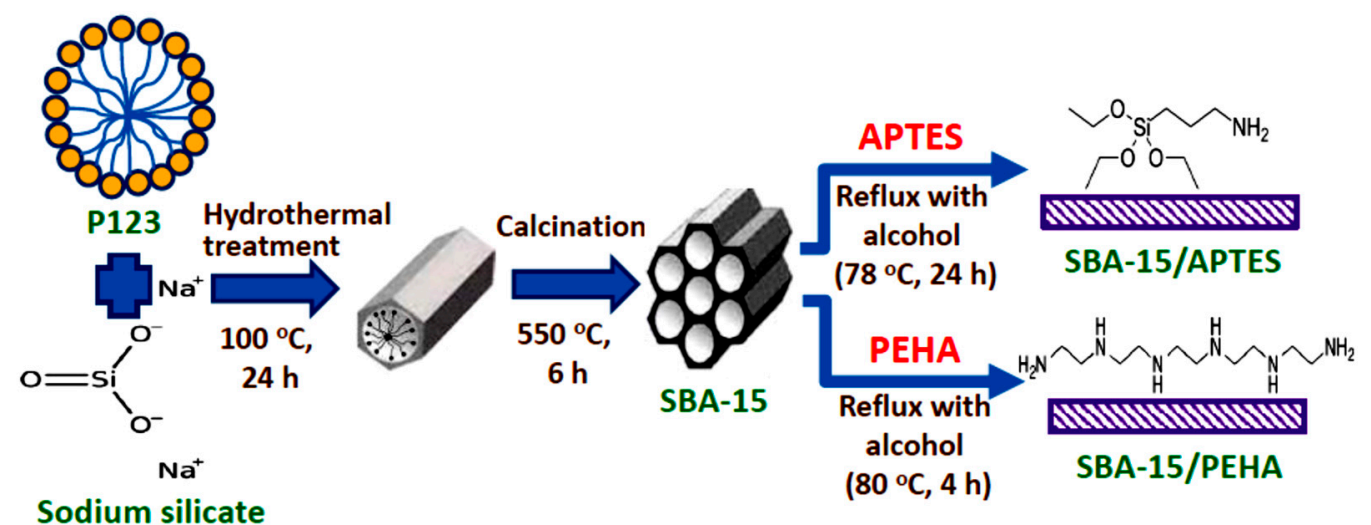

Figure 1. Schematic representation of SBA-15, SBA-15/APTES, and SBA-15/PEHA synthesis.

\subsection{Characterization of the Silica Specimens}

The pore characteristics and surface area of the mesoporous silica specimens were investigated using a $\mathrm{N}_{2}$ sorption experiment at $77 \mathrm{~K}$ by using a Micrometrics ASAP 2020 apparatus (Norcross, GA, USA). The surface functional groups of the amino-modified SBA-15 samples were inspected by a Shimadzu FTIR-8300 analyzer (Nakagyo-ku, Kyoto, Japan). The mesophases and crystalline phases of the silica specimens were assembled on an X'pert pro system X-ray diffractometer (XRD, PANalytical, Malvern, UK) equipped with $\mathrm{Cu}-\mathrm{k} \alpha$ radiation. The mesoporous structure of the functionalized and unfunctionalized silica materials was inspected by a JEM-2100 (JEOL, Akishima, Tokyo, Japan) transmission electron microscope (TEM). The surface morphologies of the silica specimens were observed through an S-3400N (HITCHI, Chiyoda, Tokyo, Japan) field-emission scanning electron microscope (SEM). The thermal decomposition path of the uncalcined SBA-15 was observed through a thermogravimetric analyzer (TGA, Mettler Toledo, OH, USA, model TGA/SDTA851e). $\mathrm{W} / \mathrm{W}_{0}$ represented the remaining mass of the sample.

\subsection{Adsorption Studies}

The adsorption experiments were performed to observe the adsorption performance of the mesoporous silica materials by using a bath method to study changes in solution temperature, solution $\mathrm{pH}$, agitation speed, initial TA concentration, and adsorbent dosage. For a typical experiment, $50 \mathrm{mg}$ of adsorbent (SBA-15, SBA-15/APTES, or SBA-15/PEHA) 
was put into $250 \mathrm{~mL}$ of the TA solution, and the solution was agitated constantly. The initial TA concentrations were changed from 10 to $50 \mathrm{mg} / \mathrm{L}$, adsorbent dosages from 10 to $100 \mathrm{mg}$, agitation speed from 100 to $250 \mathrm{rpm}$, solution $\mathrm{pH}$ from 2 to 5, and solution temperatures from 25 to $60^{\circ} \mathrm{C}$. After adsorption, the residual concentrations of TA at constant periods from 0 to $120 \mathrm{~min}$ were determined using the ultraviolet-visible Genesys spectrophotometer (Thermo Electron Corporation, Waltham, MA, USA). The maximum absorbance wavelength was $278 \mathrm{~nm}$. A standard solution was used to calibrate the UV-visible spectrophotometer for every analysis. The amount of TA adsorption capacity $\left(q_{t}, \mathrm{mg} / \mathrm{g}\right)$ and removal efficiency $(R, \%)$ of the adsorbents were evaluated using the formulas:

$$
\begin{gathered}
q_{t}=\frac{\left(C_{0}-C_{t}\right) V}{W} \\
R=\frac{C_{0}-C_{t}}{C_{0}} \times 100
\end{gathered}
$$

where $W(\mathrm{~g})$ is the mass of adsorbent, $C_{0}$ and $C_{t}(\mathrm{mg} / \mathrm{L})$ are the TA concentrations at the beginning and at time $t$, and $V(\mathrm{~L})$ is the volume of the TA solution.

\section{Results and Discussion}

\subsection{Analysis of Phase Features and Surface Functional Groups}

The XRD technique is frequently developed to analyze the characteristics of phase composition of silica materials in synthesis process. Figure 2 presents the XRD patterns with small-angle diffraction of silica samples obtained under different synthesis conditions. These samples exhibited three peaks at (100), (110), and (200) planes, corresponding to two-dimensional and hexagonal SBA-15 mesostructures [26]. Figure 2a displays the XRD images of the SBA-15 prepared at hydrothermal treatment time of $12-72 \mathrm{~h}$. The peak intensity increased with an increase in hydrothermal time, indicating that increasing the hydrothermal time can help the formation of a well-ordered SBA-15 structure. The change in hydrothermal temperature from 25 to $130{ }^{\circ} \mathrm{C}$ (Figure $2 \mathrm{~b}$ ) exhibited the same trend as that of the change in hydrothermal time, indicating that enhancing hydrothermal temperature favors the formation of well-ordered mesoporous material. However, when the temperature was enhanced to $130{ }^{\circ} \mathrm{C}$, the (110) and (200) peaks disappeared, indicating that violent hydrothermal reaction may destroy the micellar template, leading to a collapse of pore structure. Therefore, the optimum hydrothermal treatment temperature is $100{ }^{\circ} \mathrm{C}$. The XRD patterns of the silica specimens synthesized at calcination time of 2-8 $\mathrm{h}$ are displayed in Figure 2c. The aim of calcination is to eliminate organic surfactants to obtain a porous solid. A high-ordered SBA-15 structure was observed by increasing the calcination time. The optimum calcination time was identified as $6 \mathrm{~h}$. The XRD images of the silica specimens synthesized at calcination temperature of $160-760{ }^{\circ} \mathrm{C}$ are presented in Figure $2 \mathrm{~d}$. The peak intensity was increased with an increase in calcination temperature, suggesting that increasing the calcination temperature was useful in the synthesis of well-ordered SBA-15 materials with hexagonal symmetry. However, at a low calcination temperature of $160{ }^{\circ} \mathrm{C}$, the three peak intensities were obviously weakened. This is probably because the surfactant template was not removed completely.

Figure 3a displays XRD images before and after amino-functionalized SBA-15 materials. The XRD data exhibit three peaks at (200), (110), and (100), implying that the pure SBA-15 sample has hexagonal symmetry. In the same situation, the amino-modified samples (SBA-15/APTES and SBA-15/PEHA) also maintained an intense (100) peak and weaker (110) and (200) peaks. The observation further confirmed that both SBA-15/APTES and SBA-15/PEHA maintained a hexagonally ordered structure after functionalization [27]. Figure $3 \mathrm{~b}$ presents an XRD pattern with a wide-range scan $\left(2 \Theta=10^{\circ}-80^{\circ}\right)$ of the SBA15 sample. A broad peak presented at diffraction angles from $20^{\circ}$ to $30^{\circ}$, indicating the formation of disordered cristobalite [28]. 

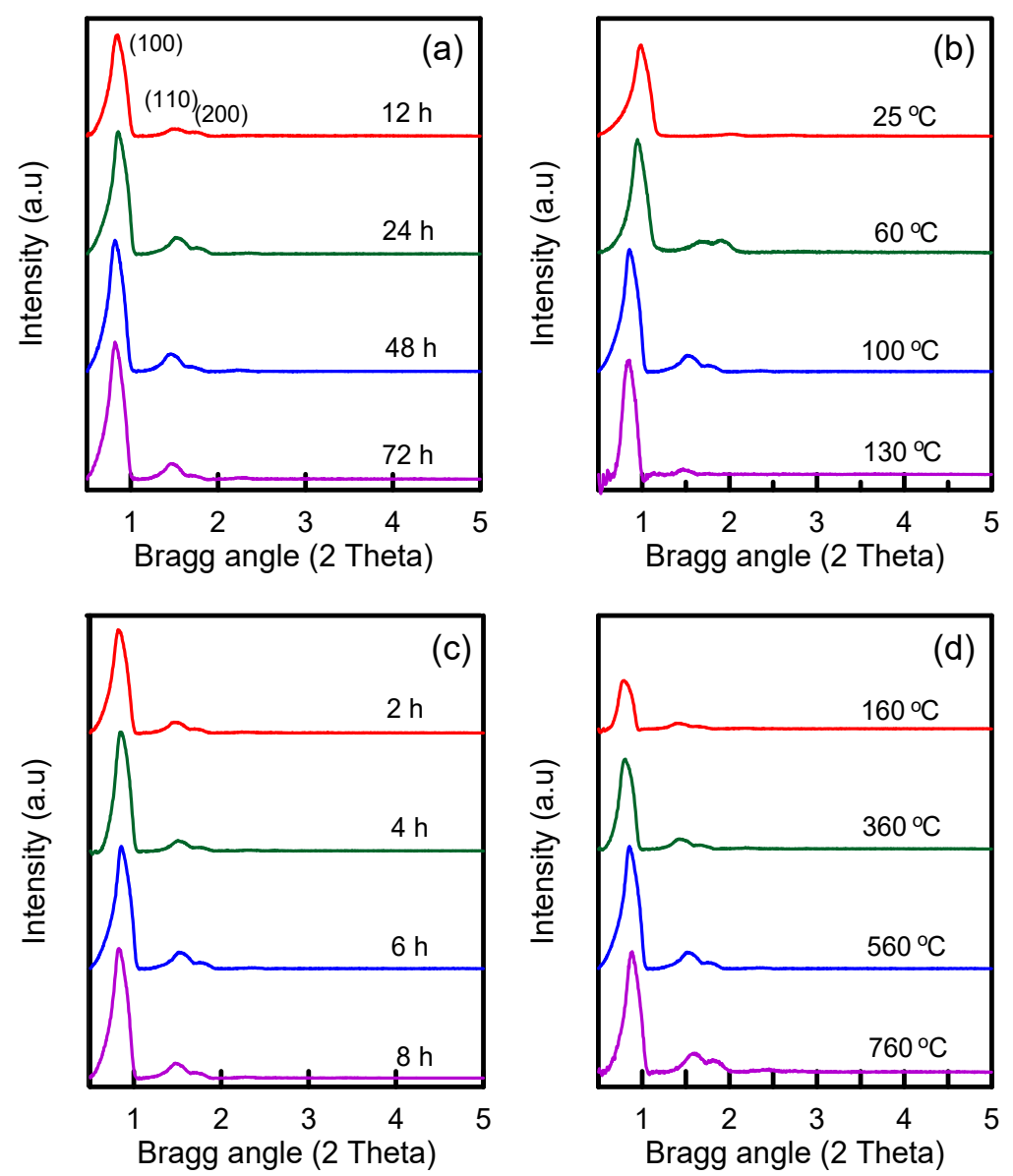

Figure 2. XRD images of SBA-15 samples prepared under various synthesis conditions: (a) Hydrothermal treatment time; (b) hydrothermal treatment temperature; (c) calcination time; (d) calcination temperature.

Qualitative identification of functional groups was accomplished by FTIR spectroscopy. The FTIR spectra of the amino-functionalized and unfunctionalized SBA-15 materials are presented in Figure 4a. In the pure SBA-15 sample, a wide peak at $3200-3700 \mathrm{~cm}^{-1}$ was caused by the presence of $\mathrm{O}-\mathrm{H}$ groups [29]. The $\mathrm{C}=\mathrm{O}$ vibrations were observed at a band of $1635 \mathrm{~cm}^{-1}$. The $\mathrm{C}=\mathrm{C}$ groups were identified at $1605 \mathrm{~cm}^{-1}$, and the band at 1375 $\mathrm{cm}^{-1}$ was the $-\mathrm{CH}_{3}$ stretching of the methyl group. The band at $980 \mathrm{~cm}^{-1}$ represented the appearance of the $\mathrm{Si}-\mathrm{OH}$ groups, and $\mathrm{Si}-\mathrm{O}-\mathrm{Si}$ groups were located at 790 and 450 $\mathrm{cm}^{-1}$ [30]. In the SBA-15/APTES and SBA-15/PEHA samples, amino group stretching vibrations were found at 692,1499 , and $1572 \mathrm{~cm}^{-1}$ [31]. This verified that amino groups were grafted onto the silica surface. Anbia and Salehi [32] observed that broad $-\mathrm{NH}_{2}$ vibrations appeared at $3250-3450 \mathrm{~cm}^{-1}$ in amino-modified silica samples. Nevertheless, the functional group was not easily examined due to the fact that the $-\mathrm{NH}_{2}$ bands may be covered by the wide band of the -OH groups. Furthermore, SBA-15/PEHA exhibited a stronger relative amino peak intensity than SBA-15/APTES. Figure $4 \mathrm{~b}$ displays the TG curve of the uncalcined SBA-15 sample. The mass loss occurring at temperatures lower than $200{ }^{\circ} \mathrm{C}$ was caused by water evaporation. The mass loss decreased slowly with an increase in thermal decomposition temperature because a longer heating time was required for the release of the surfactant matter from the high-porosity SBA-15 structure. The differential TG curve revealed only one peak at $195^{\circ} \mathrm{C}$. Similar results were observed by Liou [33] for the thermal decomposition of an uncalcined MCM-41 sample in air. 


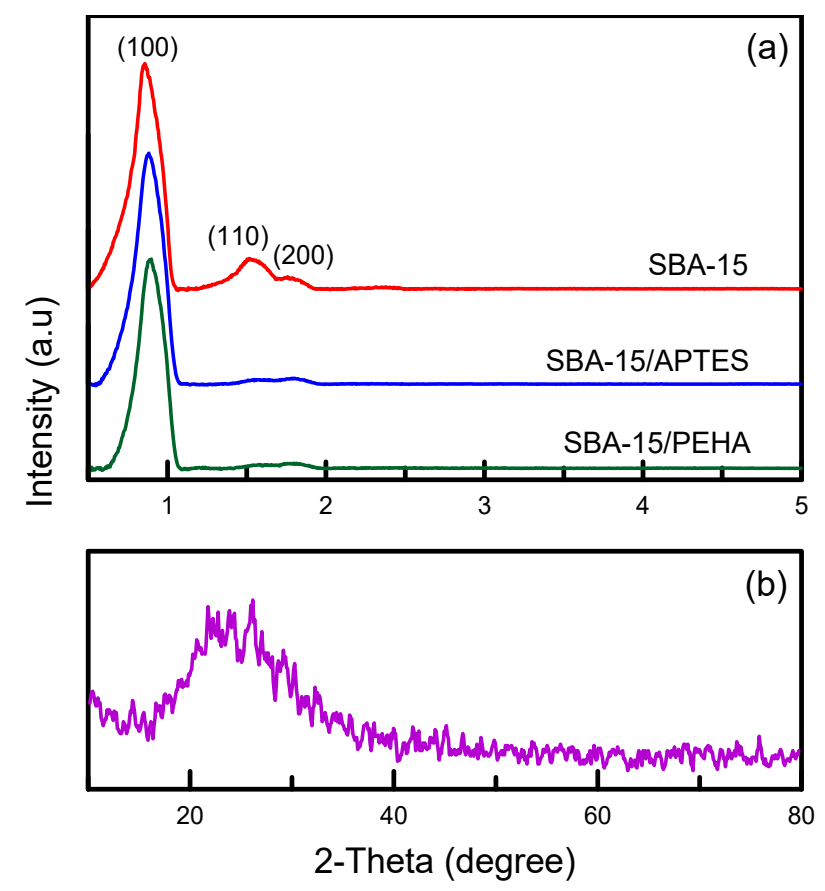

Figure 3. (a) XRD images of unfunctionalized and amino-functionalized silica samples; (b) SBA-15 sample.
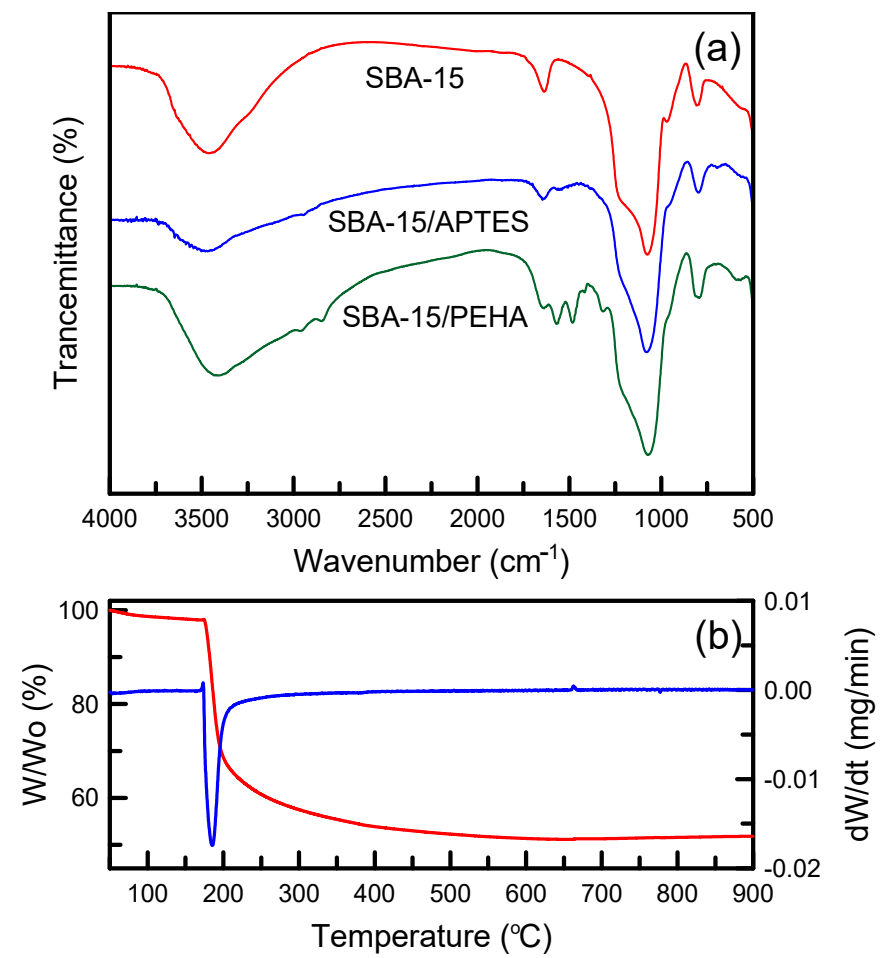

Figure 4. (a) FTIR spectra of unfunctionalized and amino-functionalized silica samples; (b) TG and DTG thermograms of uncalcined SBA-15 samples.

\subsection{Analysis of the Pore Structure}

The pore structure is an important physical property of mesoporous materials. Nitrogen isotherm method can standardly determine the porous structure and textural parameters. Figure 5 a displays the nitrogen sorption isotherms of the SBA-15 specimens prepared at hydrothermal treatment times of 12-72 h. Pure SBA-15 exhibited a type-IV hysteresis 
loop with type $\mathrm{H} 1$ at a relative pressure of $P / P_{o}=0.6-0.9$, which is characteristic of a mesoporous structure [34]. By comparing the SBA-15 samples prepared at various hydrothermal treatment times, it was revealed that the isotherms were similar. This observation indicates that an increase in hydrothermal time does not affect the mesostructure of the SBA-15 framework. Figure $5 b$ presents the features of pore size distribution. The SBA- 15 samples had pore sizes of $6.62-7.60 \mathrm{~nm}$. The SBA-15 obtained at hydrothermal times of 12-24 h had a smaller pore diameter than those obtained at 48-72 $\mathrm{h}$. These samples displayed a narrow and uniform pore distribution, implying that the pore structure of SBA-15 was stable.
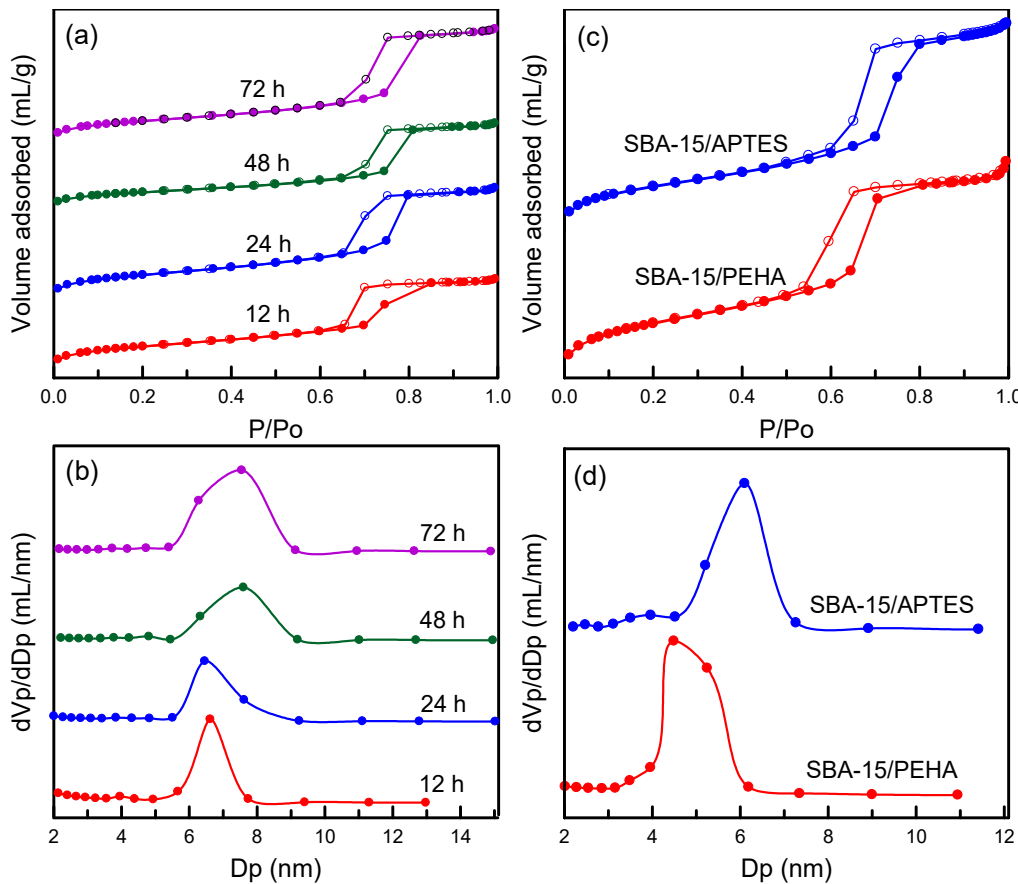

Figure 5. Nitrogen sorption isotherms and pore size distributions: (a,b) SBA-15 samples at different hydrothermal treatment times; (c,d) SBA-15/APTES and SBA-15/PEHA samples.

The isotherms of the amino-functionalized SBA-15/APTES and SBA-15/PEHA specimens are presented in Figure 5c. The two isotherms also exhibited a type-IV hysteresis loop, implying a mesoporous material. The amino-functionalized SBA-15 samples (Figure 5c) exhibited similar loops to those of pure SBA-15 (Figure 5a), indicating that the combination of SBA-15 and amino groups did not destroy the silica mesostructure. The pore size of SBA-15/APTES (6.10 nm) was larger than that of SBA-15/PEHA (4.49 nm; Figure 5d). Table 1 lists the pore volume, surface area, and mesopore fraction of the unfunctionalized and amino-functionalized silica specimens. The surface areas of the pure SBA-15 samples ranged from 546 to $766 \mathrm{~m}^{2} / \mathrm{g}$, which decreased with an increase in hydrothermal treatment time. The SBA-15 at a hydrothermal time of $48 \mathrm{~h}$ had the largest pore volume $\left(1.105 \mathrm{~cm}^{3} / \mathrm{g}\right)$. The SBA-15 samples exhibited higher surface area and pore volume as compared with the SBA-15/APTES and SBA-15/PEHA samples. The addition of amino functional groups into silica pores led to reductions in textural parameters. This is consistent with the literature [35]. Moreover, the pore volume and surface area of SBA-15/APTES $\left(0.521 \mathrm{~cm}^{3} / \mathrm{g}\right.$ and $\left.264 \mathrm{~m}^{2} / \mathrm{g}\right)$ were higher than those of SBA-15/PEHA $\left(0.272 \mathrm{~cm}^{3} / \mathrm{g}\right.$ and $\left.167 \mathrm{~m}^{2} / \mathrm{g}\right)$. The mesopore fractions of the pure SBA-15 samples ranged from $97.69 \%$ to $99.42 \%$, which increased with an increase in hydrothermal time. 
Table 1. Surface area, pore volume, and pore diameter of silica specimens.

\begin{tabular}{|c|c|c|c|c|c|c|}
\hline Sample & $\begin{array}{c}S_{\text {BET }} \\
\left(\mathrm{m}^{2} / \mathrm{g}\right)\end{array}$ & $\begin{array}{c}V_{t} \\
\left(\mathrm{~cm}^{3} / \mathrm{g}\right)\end{array}$ & $\begin{array}{c}V_{m i c} \\
\left(\mathrm{~cm}^{3} / \mathrm{g}\right)\end{array}$ & $\begin{array}{c}V_{\text {meso }} \\
\left(\mathrm{cm}^{3} / \mathrm{g}\right)\end{array}$ & $\begin{array}{c}V_{\text {meso }} / V_{t} \\
(\%)\end{array}$ & $\begin{array}{c}d_{p} \\
(\mathrm{~nm})\end{array}$ \\
\hline SBA-15-12 h & 766 & 1.038 & 0.024 & 1.014 & 97.69 & 6.62 \\
\hline SBA-15-24 h & 655 & 1.044 & 0.014 & 1.030 & 98.66 & 6.46 \\
\hline SBA-15-48 h & 604 & 1.105 & 0.009 & 1.096 & 99.19 & 7.60 \\
\hline SBA-15-72 h & 546 & 1.037 & 0.006 & 1.031 & 99.42 & 7.55 \\
\hline SBA-15/APTES & 264 & 0.521 & 0.005 & 0.516 & 99.04 & 6.10 \\
\hline SBA-15/PEHA & 167 & 0.272 & 0.005 & 0.267 & 98.16 & 4.49 \\
\hline
\end{tabular}

$\overline{\mathrm{BET}}$, specific surface area; $V_{t}$, total pore volume; $V_{\text {mic }}$, micropore volume; $V_{\text {meso }}$, mesopore volume; $d_{p}$, pore diameter (BJH desorption).

\subsection{Surface Morphology of the Mesoporous Silica Samples}

The SEM technique was utilized to observe the changes of surface morphology before and after amination of samples. The SEM pictures of SBA-15 without amination are presented in Figure 6a-d. The SBA-15 sample comprised agglomerates of rod-like particles (Figure 6a), consistent with the literature [36], whereas the SBA-15 sample acquired at a hydrothermal treatment time of $12 \mathrm{~h}$ exhibited irregular-shaped particles, indicating that the silica structure was not completely developed (Figure 6b). The SBA-15 samples obtained at hydrothermal times of 24 and 72 h had a glossy and regular surface (Figure $6 c, d$ ), indicating the formation of organized structures. This is consistent with the XRD measurements in Figure 2a. The width of the SBA-15 particles was in the range between 380 and $830 \mathrm{~nm}$. The morphology of SBA-15/APTES and SBA-15/PEHA (Figure 6e,f) did not vary as much as that of pure SBA-15, but the average width was reduced by adding the amino groups (330-610 nm for SBA-15/APTES and 300-560 nm for SBA-15/PEHA).

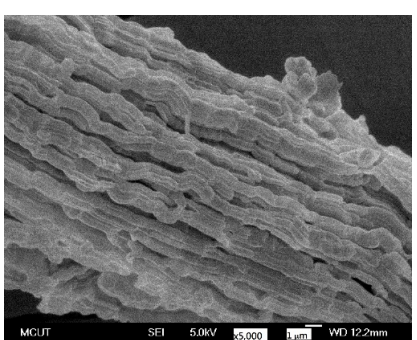

(a)

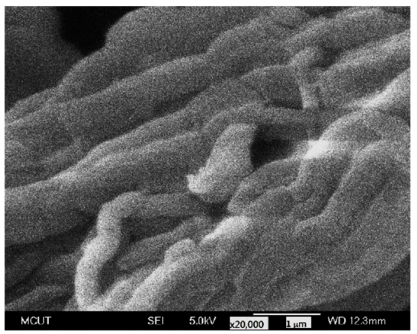

(c)

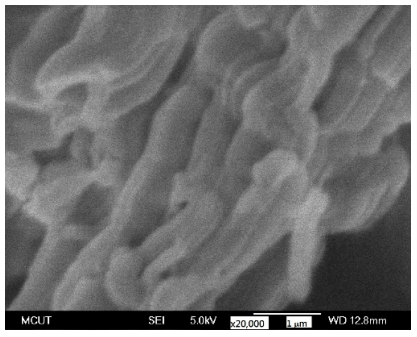

(e)

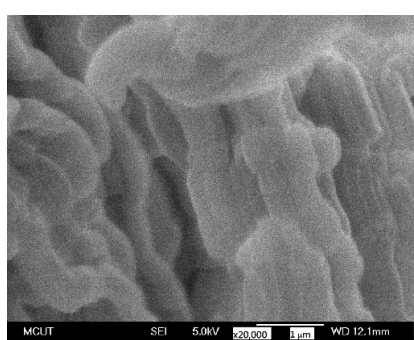

(b)

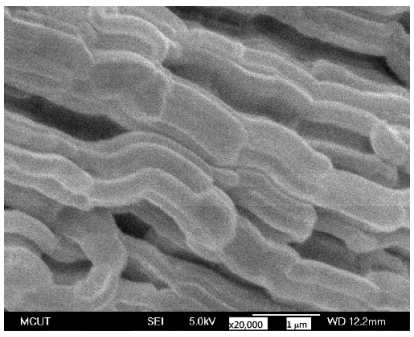

(d)

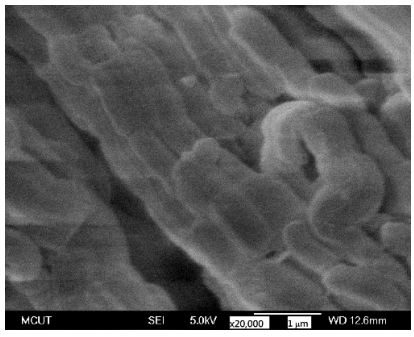

(f)

Figure 6. SEM images: (a) SBA-15; (b-d) SBA-15 synthesized at hydrothermal treatment times of 12, 24, and 72 h, respectively; (e) SBA-15/APTES; (f) SBA-15/PEHA. 
The TEM characterization technique was utilized to identify the difference of the microstructure of the prepared silica materials. The mesostructures of the amino-functionalized and unfunctionalized SBA-15 samples were investigated using TEM. Figure 7a,b verify that SBA-15 consists of parallel pore channels and highly ordered mesopores. The silica sample also possessed a large-scale hexagonal structure (Figure $7 \mathrm{~b}$ ). The mesostructure was formed through the self-assembly of surfactant micelles and silicate species [37]. The average pore size of $7.80 \mathrm{~nm}$ was similar to the $\mathrm{N}_{2}$ adsorption test in Figure $5 \mathrm{~b}$. After the amination reaction, the SBA-15/APTES (Figure 7c) and SBA-15/PEHA (Figure 7d) morphology was analogous to pure SBA-15. However, the pore diameters were reduced to 6.25 and $5.00 \mathrm{~nm}$, which was attributed to the amino group coating on the silica surface.

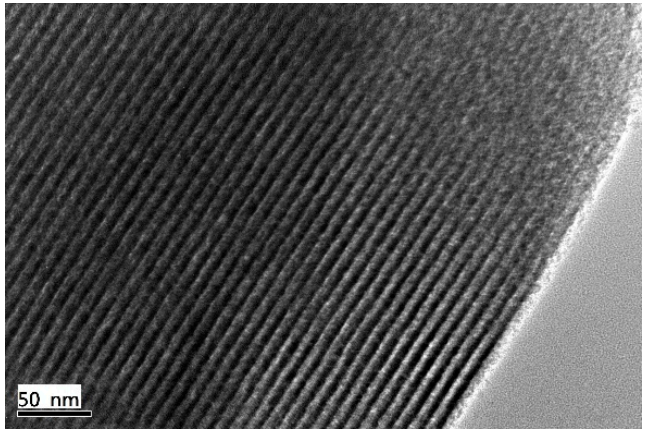

(a)

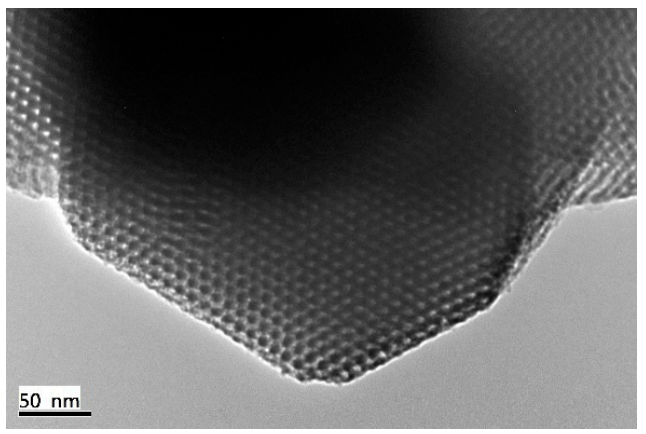

(c)

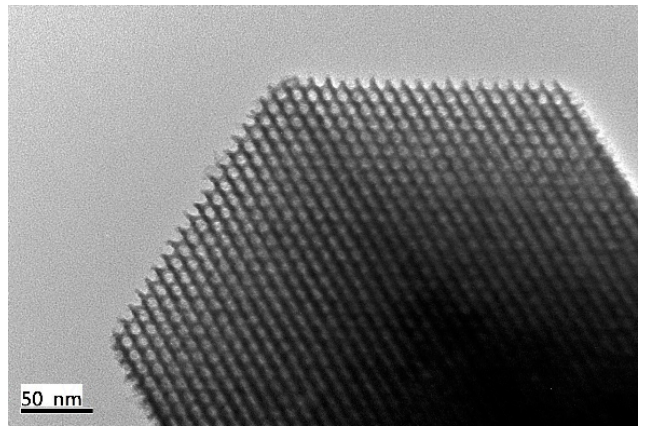

(b)

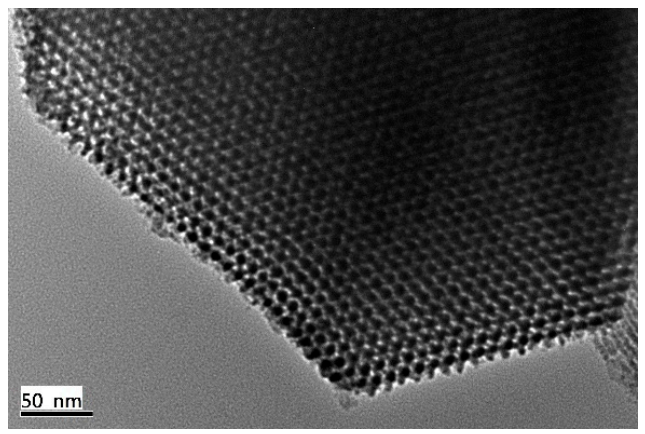

(d)

Figure 7. TEM images: (a,b) SBA-15; (c) SBA-15/APTES; (d) SBA-15/PEHA.

\subsection{TA Adsorption Study}

TA organic compound was utilized as the adsorbate to characterize the adsorption performance of the amino-functionalized SBA-15 materials. In order to evaluate the efficacy of the prepared adsorbents, the equilibrium adsorption of the TA was studied by changing various operating conditions. In the study, different types of amino-modified silica samples were used to remove TA from the aqueous solution. The influence of contact time on the adsorption capacities of adsorbents is exhibited in Figure 8. The adsorption capacity decreased in the following order: SBA-15/APTES > SBA-15/PEHA > pure SBA-15. The hydroxyl groups on the silica surface could not supply adsorption sites sufficiently strong to interact with the TA molecules. Therefore, the pure SBA-15 sample had the lowest adsorption performance. The amino-modified SBA-15 specimens showing the higher adsorption capacity can be explained as follows: Typically, amino groups are favorable to the adsorption of anionic species, and TA is an anionic compound. In the aqueous solution, the electrostatic attraction between the negatively charged TA molecules and positively charged amino groups on the SBA-15 surface $\left(-\mathrm{NH}_{3}{ }^{+}\right)$led to an increase in TA adsorption [32]. Furthermore, the SBA-15/APTES specimen had a higher surface area and pore volume than the SBA-15/PEHA specimen (Table 1) and, consequently, SBA15/APTES exhibited more efficient adsorption than SBA-15/PEHA. The contact time curves also demonstrated that TA uptake was rapid in the first few minutes, and then proceeded 
at a slower rate. The rapid adsorption during the initial adsorption period was because the adsorbent surface was unoccupied. After the adsorption reached the saturation point, the slow permeation of TA into the silica pores resulted in a reduction in the adsorption rate.

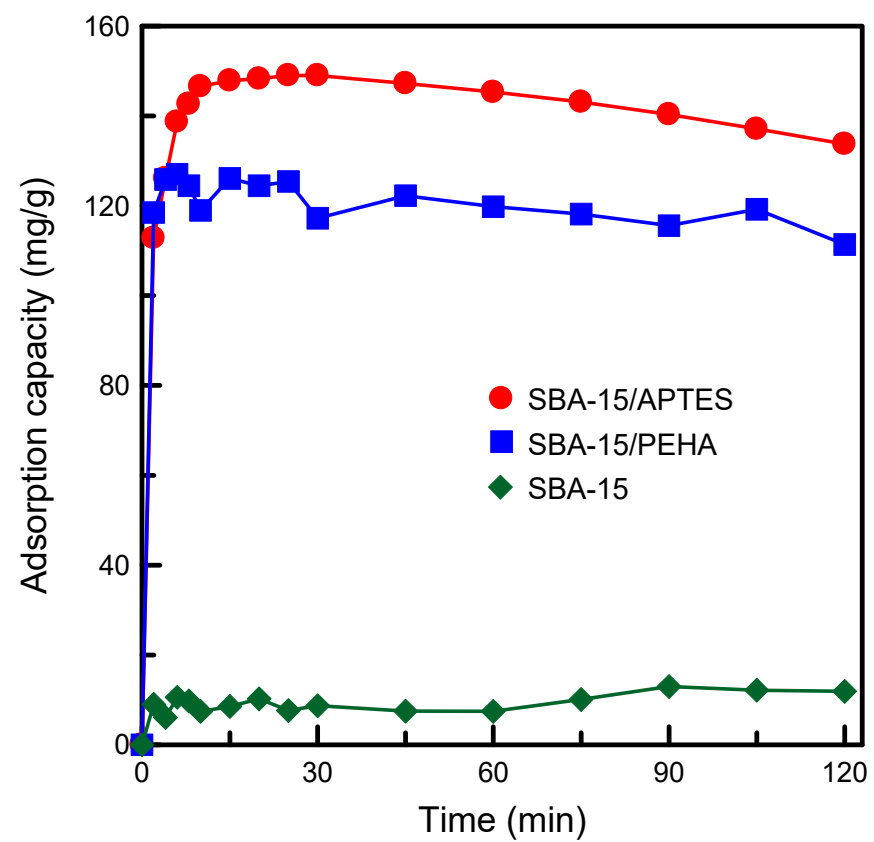

Figure 8. Effects of contact time on the adsorption performance of various kinds of adsorbents.

Figure 9a,b illustrates the influence of the initial TA concentration on adsorption capacity and the removal efficiency of amino-modified adsorbents. The adsorption capacity increased rapidly with an increase in the initial TA concentration. A higher initial TA concentration resulted in an increased mass gradient between the solute and adsorbent, which accelerated the diffusion of the TA molecules onto the SBA-15 surface. In addition, collisions between the TA and adsorbent also increased when the initial TA concentration increased. These results enhance the adsorption activity. By contrast, the removal efficiency decreased with an increase in the initial TA concentration. This was also observed in the elimination of reactive blue 21 dye from manganese oxide nanoparticles [38]. The SBA-15/APTES samples revealed a higher adsorption capacity and removal efficiency as compared with those of SBA-15/PEHA. For SBA-15/APTES specimen, a maximum removal efficiency of approximately $94 \%$ was observed at an initial concentration of $10 \mathrm{mg} / \mathrm{L}$, suggesting that the adsorbent had sufficient ability to treat trace pollutants.

The effect of adsorbent dosage on the adsorption capacity and removal efficiency of the adsorbents is displayed in Figure 9c,d. The results indicate that increasing the adsorbent dosage from 10 to $100 \mathrm{mg}$ increases the removal efficiency but decreases the adsorption capacity. Removal efficiency is increased because the available surface areas and adsorption sites are increased, whereas the reduction in adsorption capacity is because the adsorption sites are not saturated. This is consistent with a report by El-Sewify et al. on the adsorption of malachite green dye on zinc MOFs [39]. The SBA-15/APTES and SBA-15/PEHA samples displayed the maximum adsorption capacities of 485.15 and $423.33 \mathrm{mg} / \mathrm{g}$ and the highest removal efficiency of $98.61 \%$ and $87.43 \%$, respectively.

Agitation speed can influence the dispersion of solute in the solution, which is an important factor in the adsorption process. The influence of agitation speed on adsorption capacity and removal efficiency is illustrated in Figure 9e,f. For the SBA-15/APTES specimen, the removal efficiency and adsorption capacity were enhanced with an increase in the agitation speed, whereas the adsorption capacity and removal efficiency were enhanced for the SBA-15/PEHA specimen when the agitation speed increased from 100 to $150 \mathrm{rpm}$, and 
then remained constant. Increasing the agitation speed can reduce the film resistance of the adsorbent, resulting in an increase in TA adsorption.
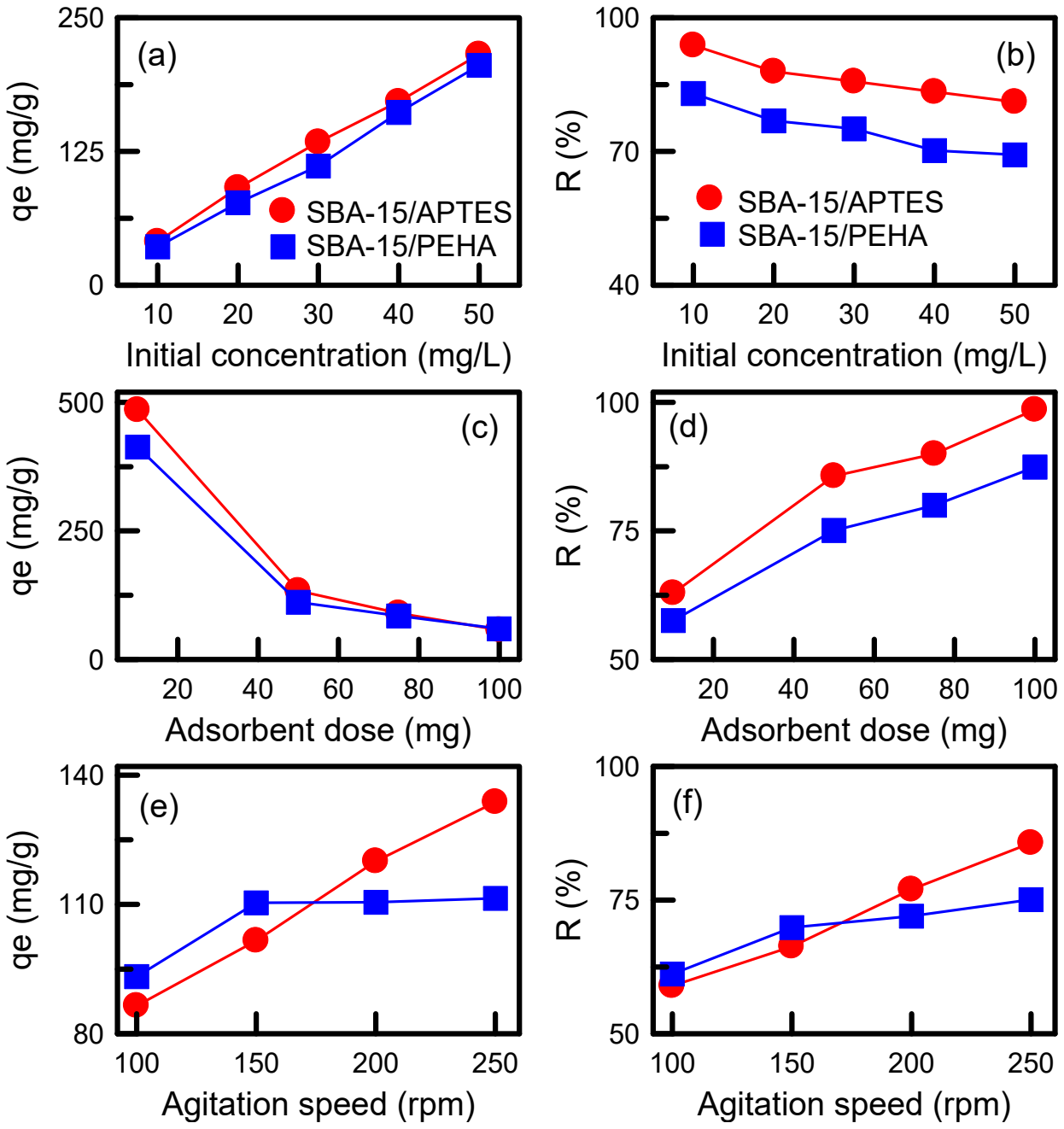

Figure 9. Effects of various adsorption conditions on the adsorption capacity and removal efficiency of adsorbents: $(\mathbf{a}, \mathbf{b})$ Initial TA concentration; $(\mathbf{c}, \mathbf{d})$ adsorbent dosage; $(\mathbf{e}, \mathbf{f})$ agitation speed.

The influence of solution $\mathrm{pH}$ on the adsorption capacity and removal efficiency of the adsorbents is presented in Figure 10a,b. The removal efficiency and adsorption capacity were increased with an increase in the $\mathrm{pH}$ values. The maximum adsorption capacities of the two adsorbents ( 133.76 and $111.37 \mathrm{mg} / \mathrm{g}$ ) were observed at $\mathrm{pH} 5$. TA exists in its molecular form at $\mathrm{pH} 4.5$. The adsorption capacity at $\mathrm{pH} 5$ was enhanced because of the increasing hydrogen bonding and electrostatic force attraction between the TA molecules and SBA-15 surface [31]. However, TA is an anionic molecule, and at a $\mathrm{pH}$ of $8-11$, the negatively charged sites on the adsorbent surface increased. The existence of excess $\mathrm{OH}^{-}$ ions compete with the TA anions, and result in the dissociation of TA during the adsorption process. Hence, this study focused on TA adsorption in acidic media.

The influence of solution temperature on the adsorption of TA is presented in Figure 10c, d. The adsorption capacity and removal efficiency were increased with a decrease in the solution temperature. The maximum removal efficiency and adsorption capacity presented at $25^{\circ} \mathrm{C}$, indicating an exothermic process. Temperature was a key factor for SBA-15/APTES in the adsorption process. However, SBA-15/PEHA was not sensitive to the solution temperature. Increasing solution temperature may cause an increase in TA solubility, weakening the interaction forces between the adsorbent and adsorbate and decreasing TA 
adsorption. Koyuncu and Okur [40] observed similar behavior in the adsorption of acid violet 90 dye on ordered mesoporous carbon.
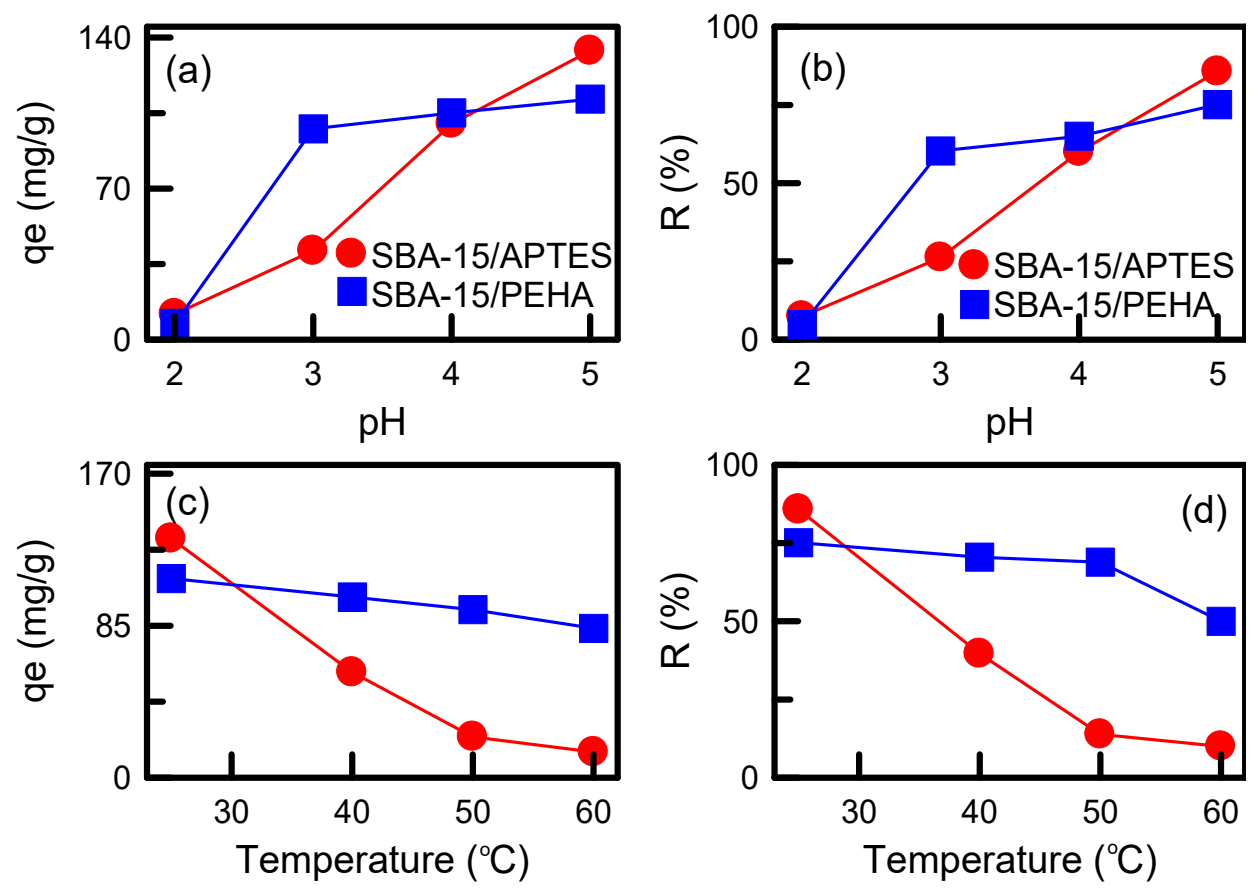

Figure 10. Effects of various adsorption conditions on the adsorption capacity and removal efficiency of adsorbents: (a,b) Solution $\mathrm{pH}$; (c,d) solution temperature.

\subsection{Thermodynamic Studies}

Thermodynamic parameters provide in-depth information on internal energy changes associated with adsorption. The standard free energies $(\Delta G, \mathrm{~kJ} / \mathrm{mol})$ for the adsorption of TA onto SBA-15/APTES and SBA-15/PEHA were calculated using the thermodynamic equilibrium constant $\left(K_{c}\right)$, which is written as below [41]:

$$
\begin{gathered}
\Delta G=-R T \ln K_{c} \\
K_{c}=\frac{C_{s}}{C_{e}}
\end{gathered}
$$

where $R$ is the gas constant $(8.314 \mathrm{~J} / \mathrm{mol}-\mathrm{K}) ; T$ is the absolute temperature $(K)$; and $C_{s}$ and $C_{e}(\mathrm{mg} / \mathrm{L})$ are the equilibrium concentration of TA on the solid and in the solution, respectively.

The enthalpy $(\Delta H, \mathrm{~kJ} / \mathrm{mol})$ and entropy $(\Delta S, \mathrm{~J} / \mathrm{mol}-\mathrm{K})$ can be estimated by the van't Hoff equation:

$$
\ln K_{c}=\frac{\Delta S}{R}-\frac{\Delta H}{R T}
$$

$\Delta S$ and $\Delta H$ can be acquired from the intercept and slope of Equation (5) (Figure 11), and Table 2 lists the thermodynamic parameters. The $\Delta G$ values were negative at 25 and $40{ }^{\circ} \mathrm{C}$, indicating that adsorption was spontaneous. However, the $\Delta G$ values increased with an increase in temperature, suggesting that the adsorption process was not feasible at a high temperature. The negative values of $\Delta H(-100.99$ and $-24.58 \mathrm{~kJ} / \mathrm{mol})$ further confirmed that the adsorption process was exothermic. The negative values of $\Delta S(-324.99$ and $-72.99 \mathrm{~J} / \mathrm{mol}-\mathrm{K}$ ) reflect the decrease in the freedom of mobility of TA at the liquid-solid interface of the adsorption process [42]. 

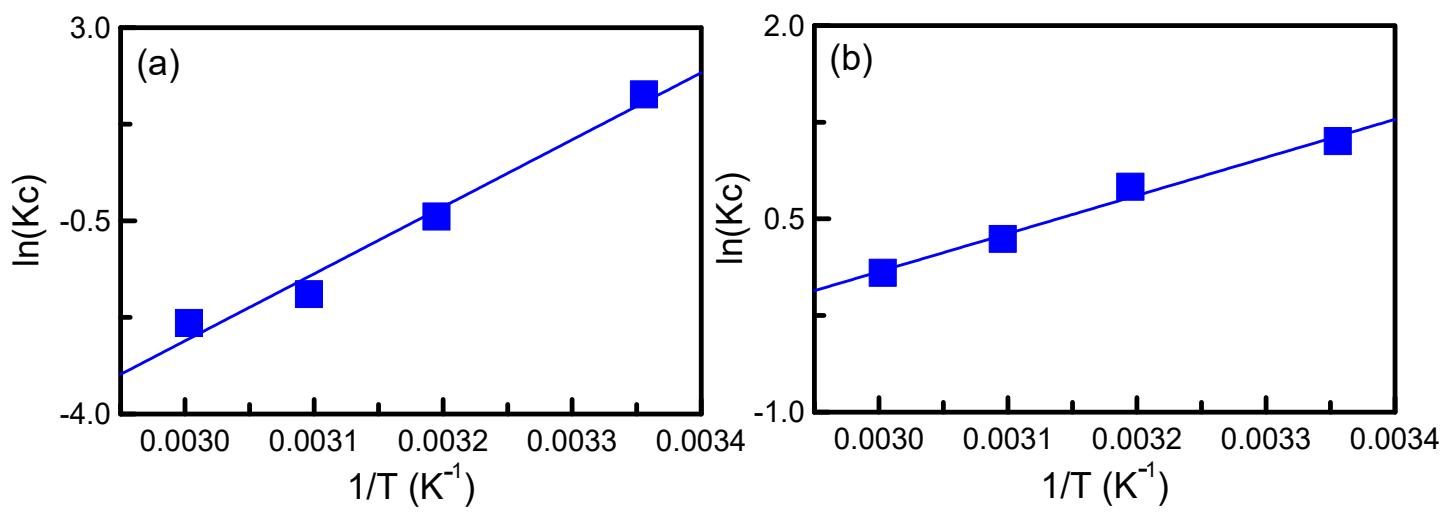

Figure 11. Plot of equilibrium constant versus temperature by using Van't Hoff equation: (a) SBA15/APTES; (b) SBA-15/PEHA.

Table 2. Thermodynamic parameters for TA adsorption onto amino-modified silica specimens.

\begin{tabular}{|c|c|c|c|c|c|c|}
\hline \multirow{2}{*}{ Sample } & \multirow{2}{*}{$\Delta S(\mathrm{~J} / \mathrm{K} \times \mathbf{m o l})$} & \multirow{2}{*}{$\Delta \mathrm{H}(\mathrm{kJ} / \mathrm{mol})$} & \multicolumn{4}{|c|}{$\Delta \mathrm{G}(\mathrm{kJ} / \mathrm{mol})$} \\
\hline & & & $25^{\circ} \mathrm{C}$ & $40^{\circ} \mathrm{C}$ & $50^{\circ} \mathrm{C}$ & $60{ }^{\circ} \mathrm{C}$ \\
\hline $\begin{array}{c}\text { SBA- } \\
\text { 15/APTES }\end{array}$ & -324.99 & -100.99 & -4.434 & -1.096 & 4.909 & 6.507 \\
\hline $\begin{array}{c}\text { SBA- } \\
\text { 15/PEHA }\end{array}$ & -72.99 & -24.58 & -2.734 & -1.953 & -0.926 & -0.227 \\
\hline
\end{tabular}

\subsection{Adsorption Isotherm Experiments}

The adsorption equilibrium between the solid and liquid surfaces in the adsorption processes can be characterized using the Langmuir and Freundlich equations. The adsorption isotherm experiments were performed using $10 \mathrm{mg}$ of SBA-15/APTES or SBA$15 /$ PEHA in $50 \mathrm{~mL}$ of TA solution. To reach adsorption equilibrium, the solution was stirred for $24 \mathrm{~h}$. The concentrations of TA were altered from 10 to $50 \mathrm{mg} / \mathrm{L}$. The solution $\mathrm{pH}$ was 5.

The linear forms of the Langmuir and Freundlich equations are [43]:

$$
\begin{aligned}
\frac{1}{q_{e}} & =\frac{1}{q_{L}}+\frac{1}{q_{L} K_{L} C_{e}} \\
\log q_{e} & =\log K_{F}+\frac{1}{n} \log C_{e}
\end{aligned}
$$

where $C_{e}(\mathrm{mg} / \mathrm{L})$ is the equilibrium concentration, $q_{e}(\mathrm{mg} / \mathrm{g})$ is the adsorption capacity, $K_{\mathrm{F}}$ and $n$ are the Freundlich constants, $K_{L}(\mathrm{~mL} / \mathrm{mg})$ is the Langmuir constant, and $q_{L}(\mathrm{mg} / \mathrm{g})$ is the maximum adsorption capacity.

The Freundlich and Langmuir equation plots are displayed in Figure 12, and the corresponding parameters are given in Table 3. The $R^{2}$ value was employed to estimate the fit of the models to the experimental data. The adsorption of TA onto SBA-15/APTES and SBA-15/PEHA followed both Langmuir and Freundlich isotherms, as shown by $R^{2}$ values (0.98-0.99) in Table 3 [44]. The maximum adsorption capacities $\left(q_{L}\right)$ of SBA-15/APTES and SBA-15/PEHA were 418.41 and $303.03 \mathrm{mg} / \mathrm{g}$, respectively. The $\mathrm{R}_{\mathrm{L}}$ values of the two adsorbents were within the range of $0-1$, with $n>1$ indicating an advantageous adsorption course. This result implies that adsorption was likely to occur [45]. 

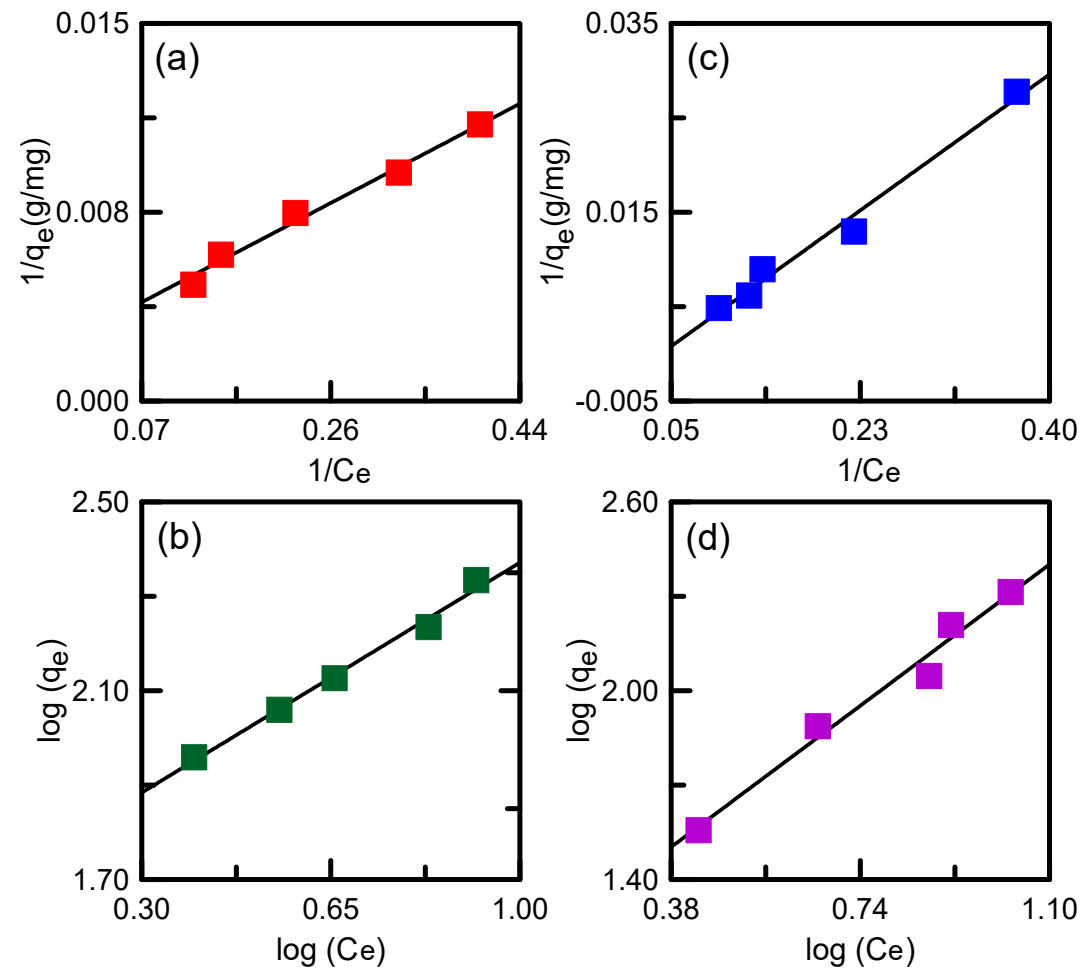

Figure 12. Plots of Langmuir model for (a) SBA-15/APTES and (c) SBA-15/PEHA; Freundlich model for (b) SBA-15/APTES and (d) SBA-15/PEHA.

Table 3. Isotherm constants for TA adsorption onto amino-modified silica specimens.

\begin{tabular}{cccccccc}
\hline \multirow{2}{*}{ Sample } & \multicolumn{4}{c}{ Langmuir } & \multicolumn{3}{c}{ Freundlich } \\
\cline { 2 - 8 } & $\boldsymbol{R}_{\boldsymbol{L}}$ & $\boldsymbol{q}_{\boldsymbol{L}} \mathbf{( \mathbf { m g } / \mathbf { g } )}$ & $\boldsymbol{K}_{\boldsymbol{L}}$ & $\boldsymbol{R}^{\mathbf{2}}$ & $\boldsymbol{n}$ & $\boldsymbol{K}_{\boldsymbol{F}}(\mathbf{m g} / \mathbf{g})$ & $\boldsymbol{R}^{\mathbf{2}}$ \\
\hline SBA-15/APTES & 0.154 & 418.41 & 0.11 & 0.986131 & 1.44 & 47.49 & 0.990632 \\
SBA-15/PEHA & 0.333 & 303.03 & 0.04 & 0.984151 & 1.02 & 10.7 & 0.978013 \\
\hline
\end{tabular}

\subsection{Kinetic Studies}

To further realize the adsorption mechanism, pseudo-first-order and pseudo-secondorder models were examined. The equations for the two models are [46]:

$$
\begin{gathered}
q_{t}=q_{e}\left(1-e^{-k_{1} t}\right) \\
\frac{t}{q_{t}}=\frac{1}{k_{2} q_{2}^{2}}+\frac{t}{q_{e}}
\end{gathered}
$$

where $k_{1}$ and $k_{2}$ are the rate constants of each model, respectively; $q_{t}$ and $q_{e}(\mathrm{mg} / \mathrm{g})$ are the adsorption capacities of adsorbents at time $t$ and at equilibrium, respectively. The solution $\mathrm{pH}$ was 5 .

Adsorption capacity versus time using Equations (8) and (9) is plotted in Figure 13. In Table $4, R^{2}$ indicates that the pseudo-second-order model provides the optimum fitting for the adsorption of TA onto SBA-15/APTES and SBA-15/PEHA, suggesting that the adsorption was mainly controlled by chemisorption. Furthermore, the experimental $q_{e}$ values (215.78 and $205.52 \mathrm{mg} / \mathrm{g}$ ) are similar to the calculated $q_{e}$ values $(218.34$ and $206.61 \mathrm{mg} / \mathrm{g}$ ). 

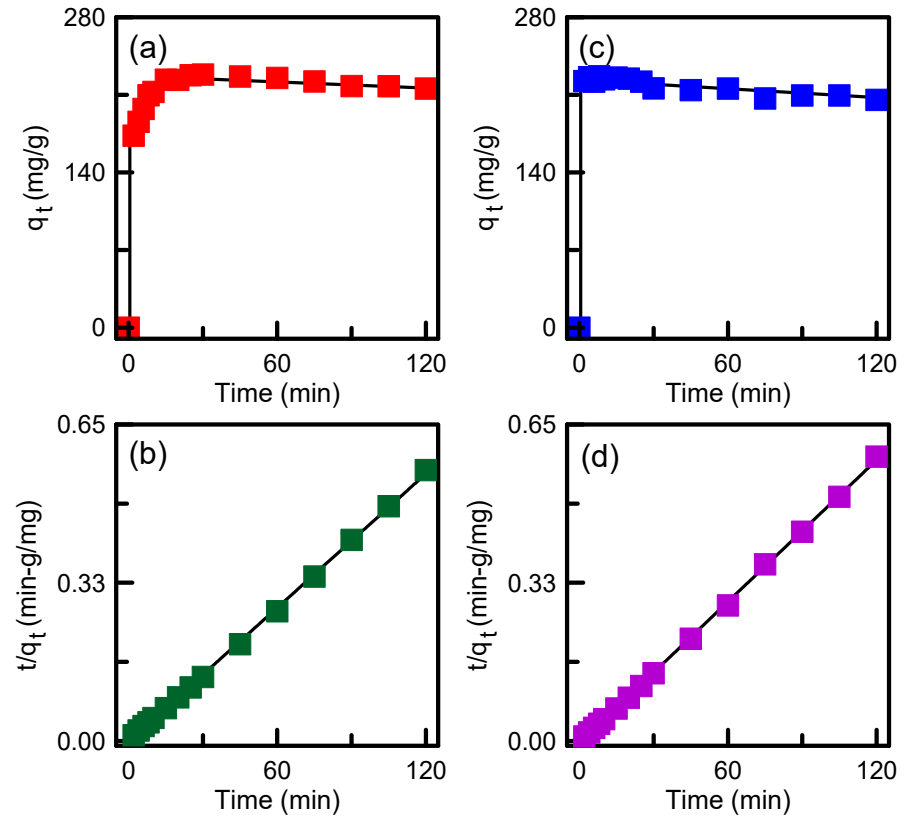

Figure 13. Plots of pseudo-first-order model for (a) SBA-15/APTES and (c) SBA-15/PEHA; pseudosecond-order model for (b) SBA-15/APTES and (d) SBA-15/PEHA.

Table 4. Kinetics constants for TA adsorption onto amino-modified silica specimens.

\begin{tabular}{cccc}
\hline \multirow{2}{*}{ Model } & \multirow{2}{*}{ Parameter } & \multicolumn{2}{c}{ Value } \\
\cline { 3 - 4 } & & SBA-15/APTES & SBA-15/PEHA \\
\hline & $q_{e, \text { experiment }}(\mathrm{mg} / \mathrm{g})$ & 215.78 & 205.52 \\
Pseudo-first-order & $q_{e, \text { calculated }}(\mathrm{mg} / \mathrm{g})$ & 0.6473 & 218.08 \\
adsorption kinetic & $k_{1}\left(\mathrm{~min}^{-1}\right)$ & 0.97224 & 43.49 \\
& $R^{2}$ & 215.78 & 0.98146 \\
Pseudo-second-order & $q_{e, \text { experiment }}(\mathrm{mg} / \mathrm{g})$ & 218.34 & 205.52 \\
adsorption kinetic & $q_{e, \text { calculated }}(\mathrm{mg} / \mathrm{g})$ & 0.02 & 206.61 \\
& $k_{2}\left(\mathrm{~min}^{-1}\right)$ & 0.99971 & 0.01 \\
& $R^{2}$ & & 0.99978 \\
\hline
\end{tabular}

Table 5 displays the maximum adsorption capacity of TA onto different adsorbents. The SBA-15/APTES and SBA-15/PEHA samples prepared in this study had high adsorption capacities (485 and $413 \mathrm{mg} / \mathrm{g}$, respectively) as compared with adsorbents used in other studies. Thus, the amino-functionalized and mesoporous silica-based materials synthesized in this work could be utilized as efficient adsorbents for the elimination of TA from aqueous solutions.

Table 5. Maximum adsorption capacity for TA adsorption onto various adsorbents.

\begin{tabular}{ccc}
\hline Adsorbent & $\boldsymbol{q} \mathbf{( m g / g )}$ & Reference \\
\hline Montmorillonite & 219 & {$[47]$} \\
Activated carbon & 162 & {$[48]$} \\
Clay & 138 & {$[49]$} \\
Polyaniline & 117 & {$[50]$} \\
Chitosan/NaOH/fly ash & 244 & {$[51]$} \\
composite & & {$[52]$} \\
Porous crosslinked & 248 & {$[53]$} \\
polystyrene & 87 & Present work \\
Biochar & 485 & Present work \\
SBA-15/APTES & 413 &
\end{tabular}




\section{Conclusions}

The preparation of amino-functionalized SBA-15 composites for the adsorption of TA was investigated in the present work. The XRD observations indicate that the mesostructure of SBA-15 materials is highly sensitive to hydrothermal time, hydrothermal temperature, calcination time, and calcination temperature. The FTIR analysis revealed that amino groups were successfully grafted onto the SBA-15 surface, and TEM verified that the silica pore framework remained nearly unchanged after the amination reaction. The surface area and pore volume of the adsorbents were SBA-15 > SBA-15/APTES > SBA-15/PEHA. The adsorption efficiency of SBA-15 material was enhanced by way of surface modification with amino groups, and the adsorption capacity increased because of the formation of an electrostatic interaction and hydrogen bond between the adsorbent surface and TA molecules. SBA-15/APTES exhibited higher adsorption activity for the removal of TA than SBA-15/PEHA. The adsorption capacities were increased with increases in the initial TA concentration, agitation speed, and solution $\mathrm{pH}$. However, increasing the adsorbent dosage and solution temperature resulted in a reduction in adsorption capacity. Pure SBA-15 had little affinity for TA in aqueous solution. Amino-functionalized SBA-15 presented higher TA adsorption efficiency than pure SBA-15. The results of the study identified high-efficiency adsorbents that could be applied to the removal of organic pollutants. As future perspectives, we propose to use magnetic iron compounds to facilitate the separation for larger scale application, as well as to adsorb other pollutants of interest, for example, hazardous heavy metals, and finally to a real industrial wastewater.

Author Contributions: Conceptualization, T.-H.L.; methodology, G.-W.C.; formal analysis, S.Y.; investigation, G.-W.C.; data curation, S.Y.; writing (original draft), T.-H.L.; writing (review and editing), T.-H.L. All authors have read and agreed to the published version of the manuscript.

Funding: This research received no external funding.

Institutional Review Board Statement: Not applicable.

Informed Consent Statement: Not applicable.

Data Availability Statement: Data sharing not applicable.

Acknowledgments: The authors gratefully appreciate the financial supports by the Ministry of Science and Technology (MOST) of Taiwan through project no. MOST 110-2221-E-131-008-MY2.

Conflicts of Interest: The authors declare no conflict of interest.

\section{References}

1. Zielinska, A.; Costa, B.; Ferreira, M.V.; Miguéis, D.; Louros, J.M.S.; Durazzo, A.; Lucarini, M.; Eder, P.; Chaud, M.V.; Morsink, M.; et al. Nanotoxicology and nanosafety: Safety-by-design and testing at a glance. Int. J. Environ. Res. Public Health 2020, $17,4657$. [CrossRef] [PubMed]

2. Souto, E.B.; Silva, G.F.; Dias-Ferreira, J.; Zielinska, A.; Ventura, F.; Durazzo, A.; Lucarini, M.; Novellino, E.; Santini, A. Nanopharmaceutics: Part I-Clinical trials legislation and good manufacturing practices (GMP) of nanotherapeutics in the EU. Pharmaceutics 2020, 12, 146. [CrossRef] [PubMed]

3. Zhao, D.; Feng, J.; Huo, Q.; Melosh, N.; Fredrickson, G.H.; Chmelka, B.F.; Stucky, G.D. Triblock copolymer syntheses of mesoporous silica with periodic 50 to 300 angstrom pores. Science 1998, 279, 548-552. [CrossRef]

4. Xian, Q.; Chen, L.; Fan, W.; Liu, Y.; He, X.; Dan, H.; Zhu, L.; Ding, Y.; Duan, T. Facile synthesis of novel Bi ${ }^{0}$-SBA-15 adsorbents $^{-}$ by an improved impregnation reduction method for highly efficient capture of iodine gas. J. Hazard. Mater. 2022, $424,127678$. [CrossRef]

5. Chongdar, S.; Bhattacharjee, S.; Azad, S.; Bal, R.; Bhaumik, A. Selective N-formylation of amines catalysed by Ag NPs festooned over amine functionalized SBA-15 utilizing $\mathrm{CO}_{2}$ as $\mathrm{C} 1$ source. Mol. Catal. 2021, 516, 111978. [CrossRef]

6. Vargas-Osorio, Z.; Klotschan, A.; Arango-Ospina, M.; Piñeiro, Y.; Liverani, L.; Rivas, J.; Michálek, M.; Galusek, D.; Boccaccini, A.R. Effect of glycerol and $\mathrm{H}_{3} \mathrm{PO}_{4}$ on the bioactivity and degradability of rod-like SBA-15 particles with active surface for bone tissue engineering applications. Microporous Mesoporous Mat. 2022, 329, 111543. [CrossRef]

7. Su, H.L.; Xu, L.; Hu, X.J.; Chen, F.F.; Li, G.; Yang, Z.K.; Wang, L.P.; Li, H.L. Polymer grafted mesoporous SBA-15 material synthesized via metal-free ATRP as pH-sensitive drug carrier for quercetin. Eur. Polym. J. 2021, 148, 110354. [CrossRef] 
8. Chen, C.; Wang, H.; Chen, Y.; Wei, X.; Zou, W.; Wan, H.; Dong, L.; Guan, G. Layer-by-layer self-assembly of hierarchical flower-like HKUST-1-based composite over amino-tethered SBA-15 with synergistic enhancement for $\mathrm{CO}_{2}$ capture. Chem. Eng. J. 2021, 413, 127396. [CrossRef]

9. Rajabi, Z.; Javanbakht, M.; Hooshyari, K.; Adibi, M.; Badiei, A. Phosphoric acid doped polybenzimidazole based polymer electrolyte membrane and functionalized SBA-15 mesoporous for elevated temperature fuel cell. Int. J. Hydrogen Energy 2021, 46, 33241-33259. [CrossRef]

10. Chiani, E.; Azizi, S.N.; Ghasemi, S. PdCu bimetallic nanoparticles decorated on ordered mesoporous silica (SBA-15) /MWCNTs as superior electrocatalyst for hydrogen evolution reaction. Int. J. Hydrogen Energy 2021, 46, 25468-25485. [CrossRef]

11. Wang, Z.; Sun, R.; Wang, P.; Wang, W. Unit-cell wide SBA-15 type mesoporous silica nanoparticles. Microporous Mesoporous Mat. 2021, 328, 111491. [CrossRef]

12. Wei, W.; Li, J.; Han, X.; Yao, Y.; Zhao, W.; Han, R.; Li, S.; Zhang, Y.; Zheng, C. Insights into the adsorption mechanism of tannic acid by a green synthesized nano-hydroxyapatite and its effect on aqueous $\mathrm{Cu}(\mathrm{II})$ removal. Sci. Total Environ. 2021, 778, 146189. [CrossRef] [PubMed]

13. Yan, W.; Shi, M.; Dong, C.; Liu, L.; Gao, C. Applications of tannic acid in membrane technologies: A review. Adv. Colloid Interface Sci. 2020, 284, 102267. [CrossRef]

14. Kumar, R.; Barakat, M.A.; Soliman, E.M. Removal of tannic acid from aqueous solution by magnetic carbohydrate natural polymer. J. Ind. Eng. Chem. 2014, 20, 2992-2997. [CrossRef]

15. Katheresan, V.; Kansedo, J.; Lau, S.Y. Efficiency of various recent wastewater dye removal methods: A review. J. Environ. Chem. Eng. 2018, 6, 4676-4697. [CrossRef]

16. Aryee, A.A.; Dovi, E.; Li, Q.; Han, R.; Li, Z.; Qu, L. Magnetic biocomposite based on peanut husk for adsorption of hexavalent chromium, Congo red and phosphate from solution: Characterization, kinetics, equilibrium, mechanism and antibacterial studies. Chemosphere 2022, 287, 132030. [CrossRef]

17. Castaldo, R.; Avolio, R.; Cocca, M.; Errico, M.E.; Avella, M.; Gentile, G. Amino-functionalized hyper-crosslinked resins for enhanced adsorption of carbon dioxide and polar dyes. Chem. Eng. J. 2021, 418, 129463. [CrossRef]

18. Melnyk, I.V.; Tomina, V.V.; Stolyarchuk, N.V.; Seisenbaeva, G.A.; Kessler, V.G. Organic dyes (acid red, fluorescein, methylene blue) and copper(II) adsorption on amino silica spherical particles with tailored surface hydrophobicity and porosity. J. Mol. Liq. 2021, 336, 116301. [CrossRef]

19. Tang, Y.; Li, M.; Mu, C.; Zhou, J.; Shi, B. Ultrafast and efficient removal of anionic dyes from wastewater by polyethyleneiminemodified silica nanoparticles. Chemosphere 2019, 229, 570-579. [CrossRef]

20. Babapour, M.; Dehghani, M.H.; Alimohammadi, M.; Arjmand, M.M.; Salari, M.; Rasuli, L.; Mubarak, N.M.; Khan, N.A. Adsorption of $\mathrm{Cr}(\mathrm{VI})$ from aqueous solution using mesoporous metal-organic framework-5 functionalized with the amino acids: Characterization, optimization, linear and nonlinear kinetic models. J. Mol. Liq. 2022, 345, 117835. [CrossRef]

21. Huang, X.Y.; Mao, X.Y.; Bu, H.T.; Yu, X.Y.; Jiang, G.B.; Zeng, M.H. Chemical modification of chitosan by tetraethylenepentamine and adsorption study for anionic dye removal. Carbohydr. Res. 2011, 346, 1232-1240. [CrossRef] [PubMed]

22. Liou, T.H.; Liou, Y.H. Utilization of rice husk ash in the preparation of graphene-oxide-based mesoporous nanocomposites with excellent adsorption performance. Materials 2021, 14, 1214. [CrossRef] [PubMed]

23. Liou, T.H.; Hung, L.W.; Liu, C.L.; Zhang, T.Y. Direct synthesis of nano titania on highly-ordered mesoporous SBA-15 framework for enhancing adsorption and photocatalytic activity. J. Porous Mat. 2018, 25, 1337-1347. [CrossRef]

24. Nnadozie, E.C.; Ajibade, P.A. Adsorption, kinetic and mechanistic studies of $\mathrm{Pb}(\mathrm{II})$ and $\mathrm{Cr}(\mathrm{VI})$ ions using APTES functionalized magnetic biochar. Microporous Mesoporous Mat. 2020, 309, 110573. [CrossRef]

25. Zheng, W.T.; Huang, K.; Dai, S. Solvothermal and template-free synthesis of N-Functionalized mesoporous polymer for amine impregnation and $\mathrm{CO}_{2}$ adsorption. Microporous Mesoporous Mat. 2019, 290, 109653. [CrossRef]

26. Olejnik, A.; Goscianska, J. On the importance of physicochemical parameters of copper and aminosilane functionalized mesoporous silica for hydroxychloroquine release. Mater. Sci. Eng. C 2021, 130, 112438. [CrossRef]

27. Putz, A.-M.; Ciopec, M.; Negrea, A.; Grad, O.; Ianasi, C.; Ivankov, O.I.; Milanovic, M.; Stijepovic, I.; Almásy, L. Comparison of structure and adsorption properties of mesoporous silica functionalized with aminopropyl groups by the co-condensation and the post grafting methods. Materials 2021, 14, 628. [CrossRef]

28. Liou, T.H.; Tseng, Y.K.; Liu, S.M.; Lin, Y.T.; Wang, S.Y.; Liu, R.T. Green synthesis of mesoporous graphene oxide/silica nanocomposites from rich husk ash: Characterization and adsorption performance. Environ. Technol. Innov. 2021, 22, 101424. [CrossRef]

29. Maia, D.O.; Chagas, A.M.S.; Araújo, A.M.M.; Júnior, A.V.M.; Ferreira, I.M.L.; Lemos, F.C.D.; Araujo, A.S.; Júnior, V.J.F.; Gondim, A.D. Catalytic pyrolysis of glycerol in the presence of Nickel (II) Schiff base complex supported in SBA-15: Kinetic and products (TG-FTIR and PY-CG/MS). Thermochim. Acta 2018, 669, 160-168.

30. García, A.; Rosales, M.; Thomas, M.; Golemme, G. Arsenic photocatalytic oxidation over $\mathrm{TiO}_{2}$-loaded SBA-15. J. Environ. Chem. Eng. 2021, 9, 106443. [CrossRef]

31. Wang, J.; Zheng, C.; Ding, S.; Ma, H.; Ji, Y. Behaviors and mechanisms of tannic acid adsorption on an amino-functionalized magnetic nanoadsorbent. Desalination 2011, 273, 285-291. [CrossRef]

32. Anbia, M.; Salehi, S. Removal of acid dyes from aqueous media by adsorption onto amino-functionalized nanoporous silica SBA-3. Dyes Pigment. 2012, 94, 1-9. [CrossRef] 
33. Liou, T.H. A green route to preparation of MCM-41 silicas with well-ordered mesostructure controlled in acidic and alkaline environments. Chem. Eng. J. 2011, 171, 1458-1468. [CrossRef]

34. Zhang, Y.; Qian, C.; Duan, J.; Liang, Y.; Luo, J.; Han, Y.; Hu, J.; Shi, F. Synthesis of HKUST-1 embedded in SBA-15 functionalized with carboxyl groups as a catalyst for 4-nitrophenol to 4-aminophenol. Appl. Surf. Sci. 2022, 573, 151558. [CrossRef]

35. Wu, J.; Zhu, X.; Yang, F.; Ge, T.; Wang, R. Easily-synthesized and low-cost amine-functionalized silica sol-coated structured adsorbents for $\mathrm{CO}_{2}$ capture. Chem. Eng. J. 2021, 425, 131409. [CrossRef]

36. Parlett, C.M.A.; Arandiyan, H.; Durndell, L.J.; Isaacs, M.A.; Lopez, A.T.; Wong, R.J.; Wilson, K.; Lee, A.F. Continuous-flow synthesis of mesoporous SBA-15. Microporous Mesoporous Mat. 2022, 329, 111535. [CrossRef]

37. Akti, F.; Balci, S. Synthesis of APTES and alcohol modified Sn/SBA-15 in presence of competitive ion: Test in degradation of Remazol Yellow. Mater. Res. Bull. 2022, 145, 111496. [CrossRef]

38. Patra, T.; Mohanty, A.; Singh, L.; Muduli, S.; Parhi, P.K.; Sahoo, T.R. Effect of calcination temperature on morphology and phase transformation of $\mathrm{MnO}_{2}$ nanoparticles: A step towards green synthesis for reactive dye adsorption. Chemosphere 2022, $288,132472$. [CrossRef]

39. El-Sewify, I.M.; Radwan, A.; Shahat, A.; El-Shahat, M.F.; Khalil, M.M.H. Superior adsorption and removal of aquaculture and bio-staining dye from industrial wastewater using microporous nanocubic Zn-MOFs. Microporous Mesoporous Mat. 2022, 329, 111506. [CrossRef]

40. Koyuncu, D.D.E.; Okur, M. Removal of AV 90 dye using ordered mesoporous carbon materials prepared via nanocasting of KIT-6: Adsorption isotherms, kinetics and thermodynamic analysis. Sep. Purif. Technol. 2021, 257, 117657. [CrossRef]

41. Alorabi, A.Q.; Hassan, M.S.; Alam, M.M.; Zabin, S.A.; Alsenani, N.I.; Baghdadi, N.E. Natural clay as a low-cost adsorbent for crystal violet dye removal and antimicrobial activity. Nanomaterials 2021, 11, 2789. [CrossRef]

42. Bachmann, S.A.L.; Calvete, T.; Féris, L.A. Caffeine removal from aqueous media by adsorption: An overview of adsorbents evolution and the kinetic, equilibrium and thermodynamic studies. Sci. Total Environ. 2021, 767, 144229. [CrossRef]

43. Elkartehi, M.E.; Mahmoud, R.; Shehata, N.; Farghali, A.; Gamil, S.; Zaher, A. LDH nanocubes synthesized with zeolite templates and their high performance as adsorbents. Nanomaterials 2021, 11, 3315. [CrossRef] [PubMed]

44. Sarıcı-Özdemir, Ç.; Önal, Y. Equilibrium, kinetic and thermodynamic adsorptions of the environmental pollutant tannic acid onto activated carbon. Desalination 2010, 251, 146-152. [CrossRef]

45. Guo, Y.; Huang, W.; Chen, B.; Zhao, Y.; Liu, D.; Sun, Y.; Gong, B. Removal of tetracycline from aqueous solution by MCM-41-zeolite A loaded nano zero valent iron: Synthesis, characteristic, adsorption performance and mechanism. J. Hazard. Mater. 2017, 339, 22-32. [CrossRef] [PubMed]

46. Hou, Y.; Liu, L.; He, Q.; Zhang, D.; Jin, J.; Jiang, B.; Zhao, L. Adsorption behaviors and kinetics studies of chitooligosaccharides with specific degree of polymerization on a novel ion-exchange resin. Chem. Eng. J. 2022, 430, 132630. [CrossRef]

47. An, J.H.; Dultz, S. Adsorption of tannic acid on chitosan-montmorillonite as a function of $\mathrm{pH}$ and surface charge properties. Appl. Clay Sci. 2007, 36, 256-264. [CrossRef]

48. Hsieh, C.T.; Teng, H. Influence of mesopore volume and adsorbate size on adsorption capacities of activated carbons in aqueous solutions. Carbon 2000, 38, 863-869. [CrossRef]

49. Chang, M.Y.; Juang, R.S. Adsorption of tannic acid, humic acid, and dyes from water using the composite of chitosan and activated clay. J. Colloid Interface Sci. 2004, 278, 18-25. [CrossRef]

50. Wang, J.; Ji, Y.; Ding, S.; Ma, H.; Han, X. Adsorption and Desorption Behavior of Tannic Acid in Aqueous Solution on Polyaniline Adsorbent. Chin. J. Chem. Eng. 2013, 21, 594-599. [CrossRef]

51. Agarwal, S.; Rajoria, P.; Rani, A. Adsorption of tannic acid from aqueous solution onto chitosan/NaOH/fly ash composites: Equilibrium, kinetics, thermodynamics and modeling. J. Environ. Chem. Eng. 2018, 6, 1486-1499. [CrossRef]

52. Zhang, K.; Wang, Q.; Zhou, Y.; Gao, J.; Li, C.; Jiang, X. A low-cost crosslinked polystyrene derived from environmental wastes for adsorption of phenolic compounds from aqueous solution. J. Mol. Liq. 2020, 314, 113641. [CrossRef]

53. Lawal, A.A.; Hassan, M.A.; Zakaria, M.R.; Yusoff, M.Z.M.; Norrahim, M.N.F.; Mokhtar, M.N.; Shirai, Y. Effect of oil palm biomass cellulosic content on nanopore structure and adsorption capacity of biochar. Bioresour. Technol. 2021, 332, 125070. [CrossRef] [PubMed] 